EGU2020-12298

https://doi.org/10.5194/egusphere-egu2020-12298

EGU General Assembly 2020

(c) Author(s) 2021. This work is distributed under

the Creative Commons Attribution 4.0 License.

\title{
Effects of Sensor Response and Gust Duration on Maximum Wind Gust Measurements and Data Homogenisation
}

\author{
Amir Ali Safaei Pirooz ${ }^{1}$, Richard G.J. Flay ${ }^{2}$, Lorenzo Minola ${ }^{3}$, Cesar Azorin-Molina ${ }^{4,5}$, and Deliang \\ Chen $^{6}$ \\ ${ }^{1}$ Department of Mechanical Engineering, The University of Auckland, Auckland, New Zealand (asaf433@aucklanduni.ac.nz) \\ ${ }^{2}$ Department of Mechanical Engineering, The University of Auckland, Auckland, New Zealand (r.flay@auckland.ac.nz) \\ ${ }^{3}$ Regional Climate Group, Department of Earth Sciences, University of Gothenburg, Gothenburg, Sweden \\ (lorenzo.minola@gu.se) \\ ${ }^{4}$ Regional Climate Group, Department of Earth Sciences, University of Gothenburg, Gothenburg, Sweden \\ (cesar.azorin@uv.es) \\ ${ }^{5}$ Centro de Investigaciones sobre Desertificación - Spanish National Research Council (CIDE-CSIC), Moncada (Valencia), \\ Spain (cesar.azorin@uv.es) \\ ${ }^{6}$ Regional Climate Group, Department of Earth Sciences, University of Gothenburg, Gothenburg, Sweden \\ (deliang@gvc.gu.se)
}

Wind speed data recorded using different signal-processing procedures can introduce errors in the wind speed measurements. This study aims to assess the effects of a set of various moving average filter durations and turbulence intensities on the recorded maximum gust wind speeds. For this purpose, a series of wind-tunnel experiments was carried out at the University of Auckland, New Zealand, on the widely-used Vaisala WAA151 cup anemometer. The variations of gust and peak factors, and turbulence intensities measured by the cup anemometer as a function of the averaging duration and turbulence intensity are presented. The wind-tunnel results are compared with values computed from a theoretical approach, namely random process and linear system theory, and the results were also validated against values reported in the literature where possible.

To summarise, the major findings of this experimental study are:

- The results show that increasing the effective gust duration reduces both the gust and peak factors, resulting in an underestimation of maximum gust wind speeds and an overestimation of minimum gust wind speeds.

- The maximum difference between gust factors obtained for high (e.g. 3-s to 5-s) and low (raw, unfiltered measurements) gust durations reached values of $25 \%-30 \%$ for the high turbulence conditions, and up to $5 \%-10 \%$ for low turbulence intensities.

- Gust factor ratios, an important parameter that allow the measurements from a specific gust duration to be converted to other gust durations of interest, are reported for various gust durations as a function of turbulence intensity.

- The differences and gust factor ratios computed in this study can be applied directly to full- 
scale measurements, and can be used in several research areas, including analysing and homogenisation of historical wind speed time series, comparing gust climatologies of countries where different gust durations have been adopted, and so on. These factors clearly play an essential role in meteorological, climatological and wind engineering studies. 